\title{
Pirámide de la felicidad, herramientas para alcanzar la felicidad en el trabajo
}

\author{
Pyramid of Happiness, Tools to Achieve Happiness at Work
}

Evelia López-Meza ${ }^{a}$, María D. Martínez-García ${ }^{b}$

\begin{abstract}
:
Happiness is an emotional state in which the feelings are achieve when we fulfill a dream, in the sense of job, the happiness is synonyms of productivity, it is not something ethereal or intangible, because it is important for determine the organizational culture of the company. Building a sense of belonging for the work carried out, is achieved by creatingthe positive environments, encouraging and finding vocations. For this purpose, there are tools organized in three levels: At the base are the Recognize and Recognize, the clear Goals and the Commitment, these are the essential elements that originate in the individual. The next three levels are: identify and manage toxic bosses, optimize time and deal with difficult partners, these are the components of the work environment. The following, to be proactive, combat boredom and pessimism, these are associated with efficiency and performance. The last level is Respect for oneself, it is the only element that feeds on the rest for achieve, finally, the top of the pyramid is Work Happiness.
\end{abstract}

Keywords:

Work happiness, recognition, goals, commitment, optimize time, proactivity and pessimism

Resumen:

La felicidad es un estado emocional en donde se suman sentimientos que alcanzamos cuando cumplimos un sueño, en el sentido laboral la felicidad es sinónimo de productividad y no es algo etéreo o intangible pues se ha demostrado que es esencial para determinar la cultura organizacional de las empresas. Construir un sentido de pertenencia hacia la labor desempeñada, se logra creando entornos positivos, incentivando y encontrando vocaciones. Para ello se presentan herramientas en forma de pirámide ordenadas en tres niveles: en la base se encuentran el Reconocer y Reconocernos, Metas Claras y Compromiso, estos son los elementos esenciales que tienen origen en el individuo. Los tres niveles siguientes son: Identificar y Manejar los Jefes Tóxicos, Optimizar el Tiempo y Lidiar con Compañeros Difíciles, son los componentes del entorno laboral. Siguen Ser Proactivo, Combatir el Aburrimiento y el Pesimismo, están asociados con la eficiencia y el rendimiento. En el último nivel está el Respeto por uno mismo, es el único elemento que se alimenta del resto para llegar finalmente a la cúspide de la pirámide que es La Felicidad Laboral.

Palabras Clave:

Felicidad laboral, reconocimiento, metas, compromiso, optimizar tiempo, proactividad y pesimismo

\section{Introducción}

Cuando iniciamos nuestra vida laboral lo ideal es, ocupar el puesto idóneo para involucrase en las actividades generadoras de un entorno dinámico de incesantes retos que traigan en consecuencia la felicidad y no ocupar los puestos que están simplemente vacantes, porque finalmente la felicidad no reside en la posesión del dinero, sino en el disfrute de haberlo ganado con la diversión y la estimulación moral del trabajo, sin embargo esto no siempre sucede.
Para alcanzar la felicidad en el trabajo existen herramientas que permiten hacer la transición posible, uno de ellas es la pirámide de la felicidad laboral, la cual consiste en reconocer diferentes niveles.

Los peldaños de la pirámide comienzan en la base con lo siguiente:

1. Reconocernos y Reconocer.

La motivación en las personas es un aspecto determinante en el desempeño profesional, depende de numerosos factores, como: compromiso con la organización, estilo de liderazgo, integración de los equipos de trabajo, relaciones con los compañeros,

a Autor de Correspondencia, Universidad Autónoma del Estado de Hidalgo, Instituto de Ciencias Económico Administrativas, Email: evelia.lm@hotmail.com

b Universidad Autónoma del Estado de Hidalgo, Instituto de Ciencias Económico Administrativas, Email: 
compensaciones, objetivos planteados y la tarea que se va a realizar. Reconocer consiste en diferenciar, distinguir y poner en evidencia el valor de un empleado, lo cual impacta en la felicidad del trabajador y, por ende, en la productividad. Refuerza su compromiso con la empresa y desarrolla su sentido de pertenencia, en caso contrario, representa un riesgo porque influye en la habilidad para manejar la tensión física y emocional, pues al principio de nuestra vida laboral lo hacemos con gran entusiasmo, pero pasado el tiempo vamos entrando en la rutina, llega la frustración y al final la infelicidad.

Existen diferentes formas de reconocer a un empleado, incluye: enviar carta de felicitación, reconocer públicamente, promoverlo, etc., y es conveniente hacerlo en el momento del logro, porque más vale un pequeño reconocimiento a tiempo que gran exaltación a destiempo. Sin embargo, el reconocimiento no es responsabilidad únicamente de la empresa, ya que reconocernos como personas, colegas y trabajadores es un factor que multiplica el optimismo, uno mismo debe ocuparse de comunicar y poner en evidencia los logros alcanzados y así lograr un proceso de dos vías.

2. Metas claras.

Hacen referencia al tipo de trabajo que nos gustaría tener y deben ser:

- Alcanzables, si no lo son limita nuestras capacidades.

- Concretas y fáciles de analizar, que nos identifiquen como persona.

- Realistas, considerando las capacidades personales.

- Tangibles, que se visualicen con facilidad y surjan de necesidades inmediatas o urgentes.

- Corto plazo y largo plazo, establecidas en el tiempo.

Vivir sin un plan, sin objetivos y sin metas es como estar en cualquier camino con destino a ninguna parte.

3. Sudar la camiseta, compromiso laboral.

Significa comprometerse con el equipo y conceder todas las capacidades que se tienen. Está conformado por tres componentes que reflejan un estado psicológico que en suma es el compromiso, el vínculo entre el empleado y la empresa. Para ello aprendamos a desarrollar estos elementos: ser afectivo, que es la conexión emocional con la empresa y nos permite por decisión personal permanecer en ella, y ser normativo que significa tener el sentimiento de obligación.

El compromiso laboral multiplica la felicidad de los trabajadores, como factor de retención, generador de bajo ausentismo y un elemento diferenciador de la cultura organizacional. Para crear una cultura de compromiso la empresa puede: ser flexible respecto los horarios, generar confianza a través de la comunicación eficaz, remunerar de manera justa, manejar la estrategia de retos laborales para integrar los equipos y organizar actividades recreativas o deportivas.

4. Identificar y manejar jefes tóxicos.

Un jefe tóxico trae como consecuencia en el empleado: destrucción del auto concepto, miedo, incremento de la carga laboral, anulación de estímulos, angustia y desmoralización. Presenta las siguientes características: habla siempre mal de alguien ausente, esquiva el trabajo, evita tomar decisiones difíciles, evade escuchar, tiene relaciones extra maritales en el trabajo y se muestra servil. Existen diferentes tipos: el abusivo, el que es incapaz de delegar, el que oculta información, el saboteador que menosprecia esfuerzos y el que tiene cambios bruscos de humor. Para lidiar con un jefe toxico es recomendable: evitar reacciones emocionales al abuso verbal, evidenciar todo por escrito, evaluar si realmente vale la pena el trabajo, no sentirse víctima, apoyar al jefe con sus debilidades, demostrar diplomacia, ir al ritmo de trabajo que el jefe y nunca evadirlo.

5. Optimizar el tiempo.

Uno de los factores que nos agobia se presenta cuando tenemos demasiadas actividades que hacer y nos sentimos angustiados porque no sabemos por dónde comenzar. No obstante, la capacidad de gestionar bien el tiempo es una habilidad que las empresas valoran. Para lograrlo se recomienda: primero determinar cuál es nuestra misión en la empresa, analizar las tareas que específicamente se requieren para llegar a ese objetivo, luego reflexionar que cantidad de tiempo se necesita para cumplir con cada una de las tareas, con ello estudiaremos la posibilidad de reducir el tiempo de cada tarea para llegar a optimizar y automatizar nuestro sistema de trabajo. Para lograrlo se pueden organizar las tareas por afinidad y periodos de tiempo, asignar un tiempo apropiado y siempre reservar momentos para descansar.

Se deben detectar los consumidores de tiempo, como son: las visitas imprevistas, las reuniones interminables y que no cumplen con los objetivos, el desorden y las redes sociales.

6. Lidiar con compañeros competitivos.

Es el tercer y último componente del segundo nivel, se trata de no preocuparse demasiado en ser mejor que otros y tratar siempre de ser mejor que nosotros mismos, pues ningún resultado individual va a ser superior al resultado alcanzado por un equipo. Para construir una competencia sana y sobrellevar aspectos negativos de la competencia, es recomendable: ambicionar ser mejor cada día, confiar en tus habilidades, comportarse amable, ser auténtico, hablar cordialmente con las personas competitivas y evitar trabajar en contra de ellas. Finalmente, es importante asegurarse que nuestro rendimiento sea verificable e intachable, además de hablar con el jefe sobre las estrategias con respecto al trabajo en equipo.

7. Ser proactivo. 
El término hace referencia a la actitud que una persona asume en el control absoluto de su conducta en modo dinámico y autoeficacia para el manejo de situaciones complejas y solucionar problemas. Para avanzar hacia la felicidad en el trabajo es prudente adoptar un comportamiento proactivo, ya que tiene consecuencias positivas tanto para nosotros como para la empresa. Estas últimas son quienes buscan a personas flexibles que se adapten a lo inesperado, que tengan la capacidad de anticipar situaciones adversas, que estén en búsqueda constante de nuevas oportunidades y que logren resultados concretos.

8. Combatir el aburrimiento.

El aburrimiento es un estado emocional que es producido porque queremos implicarnos en una actividad satisfactoria, pero no conseguimos hacerlo, por ello combatirlo en nuestra rutina de trabajo es el mayor reto porque nos resta energía y nos hace infelices. Existen diferentes factores físicos que debemos evitar: la mala iluminación y ventilación en el área laboral, porque ambos influyen para que una persona se sienta cansada, irritada y con sueño, por otro lado planear objetivos inalcanzables o tareas interminables nos hace sentir fatigados y frustrados. Para salir de ese estado es recomendable plantear objetivos claros y alcanzables y tomar sanos descansos durante la jornada laboral.

9. Presentismo laboral.

Permanecer más horas de las necesarias en nuestro trabajo no es sinónimo de productividad, pues el rendimiento de una empresa no está relacionada con el tiempo que un empleado trabaja. Debemos evitar pérdidas de tiempo en otras actividades como es el uso inadecuado del internet o pasar mucho tiempo en las llamadas telefónicas, esta actitud es totalmente responsabilidad del trabajador y afecta el clima laboral y la productividad.

10. Respeto por uno mismo.

Es el último elemento de la pirámide y se refiere al derecho que surge de la dignidad humana sobre respetarse y exigir que nos respeten. Actuar de acuerdo a principios y valores, significa reflexionar que si desconfiamos de nosotros mismos nuestra mente hará lo posible por llevarnos a una dirección diferente, por lo tanto, toma las riendas, aprende a valorarte y afirma tu derecho y amor propio. 1

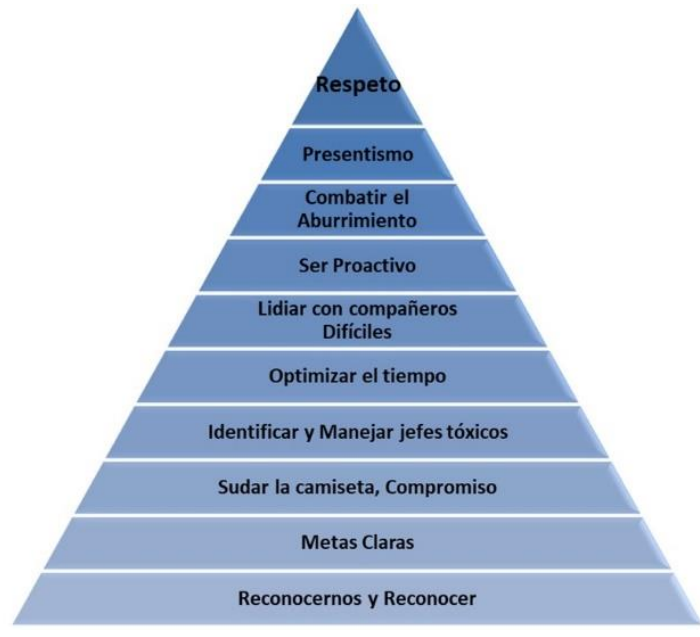

Figura 1. Pirámide de la felicidad

Una vez alcanzados los peldaños de la pirámide, se llega a la anhelada felicidad laboral o bien lo más cercano a ello. La pirámide de la felicidad es un libro que nos ayuda a reflexionar sobre las dificultades que encontramos en el trabajo y nos brinda herramienta para lidiar con ellas. En la administración de empresas un elemento que siempre ha interesado a los administradores es, el bienestar del capital humano, de ello depende la buena consecución de metas. No obstante, las actividades propias del día a día laboral han vulnerado el principio básico humano, la felicidad. La pirámide nace como respuesta para aquellas personas que busquen estabilidad emocional en el trabajo y para los administradores como una herramienta para visualizarlo desde un enfoque más humano.

\section{Referencias}

[1] Hildemaro, I. (2015). Pirámide de la felicidad laboral, herramientas para alcanzar la felicidad en el trabajo. Caracas, Venezuela: Ediciones H. Infante \& Asociados. 